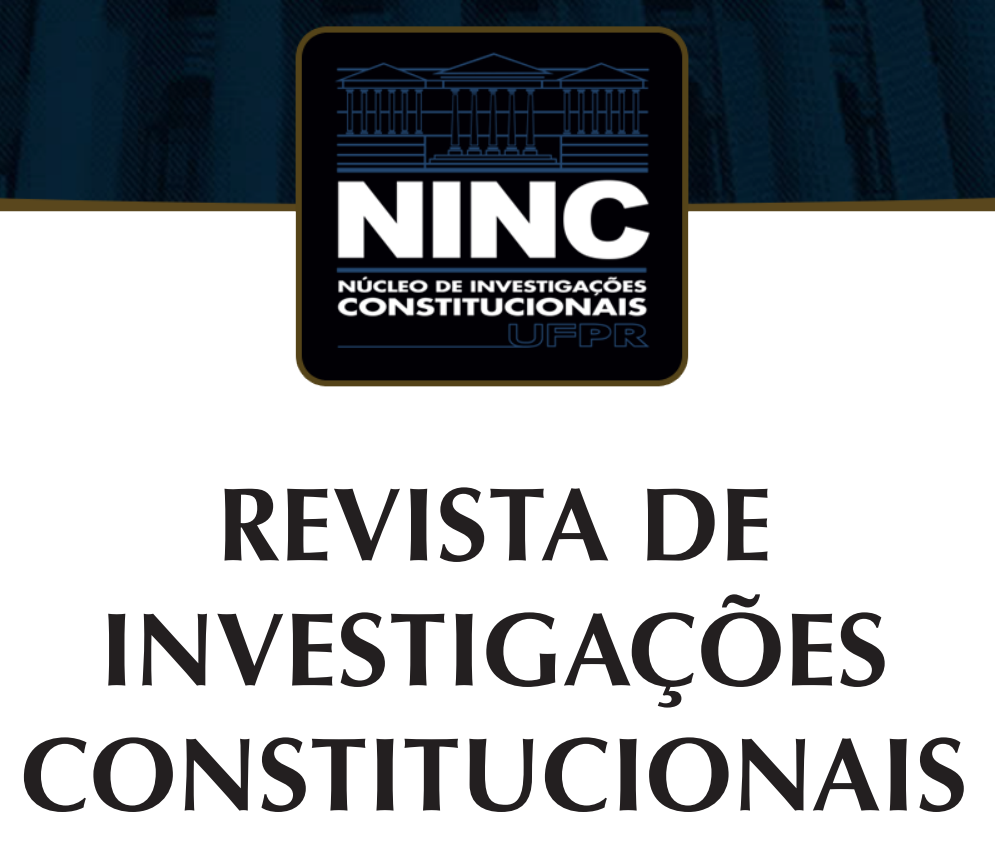

JOURNAL OF CONSTITUTIONAL RESEARCH

vol. 6 | n. 1 | janeiro/abril 2019 | ISSN 2359-5639 | Periodicidade quadrimestral Curitiba | Núcleo de Investigações Constitucionais da UFPR | www.ninc.com.br 


\title{
Estado, democracia e corrupção: equações complexas
}

\section{State, democracy and corruption: complex equations}

\author{
ROGÉRIO GESTA LEAL ${ }^{\mathrm{I}}$,

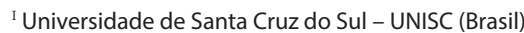 \\ gestaleal@gmail.com \\ Recebido/Received: 24.05.2018 / May $24^{\text {th }}, 2018$ \\ Aprovado/Approved: 30.04 .2019 / April 30 32019
}

\section{Resumo}

As perspectivas que cientistas políticos e juristas vêm tendo sobre o futuro o Estado Democrático de Direito na Sociedade de Riscos tem sido mais pessimista do que otimistas, em especial quando o fenômeno da corrupção é levado em conta para os fins de pensarmos a própria Democracia. Em face disto é que o presente texto pretende discutir como tem se dado esta equação entre Estado, Democracia e Corrupção, quais seus pontos mais frágeis e o que podemos fazer para superar os aspectos negativos que ela apresenta. Para tanto, vamos buscar elementos teóricos e pragmáticos que proponham formas e instrumentos objetivos para tal escopo.

Palavras-chave: Estado; democracia; corrupção; Sociedade de Riscos; mercado.

\section{Abstract}

The perspectives that political scientists and lawyers are having about the future Democratic State of Law in the Society of Risks have been more pessimistic than optimistic, especially when the phenomenon of corruption is taken into account for the purposes of thinking Democracy itself. Therefore, the present text intends to discuss how this equation has been given between State, Democracy and Corruption, what are its most fragile points and what we can do to overcome the negative aspects that it presents. To this end, we will seek theoretical and pragmatic elements that propose objective forms and instruments for such scope.

Keywords: State; democracy; corruption; Society of Risks; market.

Como citar esse artigo/How to cite this article: LEAL, Rogério Gesta. Estado, democracia e corrupção: equações complexas. Revista de Investigações Constitucionais, Curitiba, vol. 6, n. 1, p. 91-106, jan./abr. 2019. DOI: 10.5380/rinc.v6i1.59564.

* Professor Titular da Universidade de Santa Cruz do Sul - UNISC (Santa Cruz do Sul-RS, Brasil). Doutor em Direito pela Universidade Federal de Santa Catarina. Professor da FMP (Palhoça-SC, Brasil). Professor Visitante da Università Túlio Ascarelli - Roma Trè, Universidad de La Coruña - Espanha (A Coruña-España) e Universidad de Buenos Aires (Buenos Aires, Argentina). Professor da Escola Nacional de Formação e Aperfeiçoamento da Magistratura - ENFAM. Membro da Rede de Direitos Fundamentais-REDIR, do Conselho Nacional de Justiça-CNJ (Brasília-DF, Brasil). Coordenador do Projeto de Pesquisa Internacional sobre Patologias Corruptivas. Desembargador do Tribunal de Justiça do Estado do Rio Grande do Sul. E-mail: gestaleal@gmail.com. 


\section{SUMÁRIO}

1. Notas Introdutórias; 2. Desafios à Democracia na Sociedade de Riscos; 3. A corrupção como fenômeno mundial; 4. Considerações Finais; 5. Referências.

\section{NOTAS INTRODUTÓRIAS}

As relações entre Estado, Democracia e Corrupção sempre foram tensas e marcadas por profundos desafios; a uma, porque a história tem demonstrado que estes elementos se entrecruzam constantemente, ora tendo protagonismo um, oura outro; a duas, porque o presente evidencia que a complexidade cada vez mais intensa nas relações pessoais e institucionais não tende a se esvair, ao contrário, registra força, riscos e perigos cada vez mais inéditos, provocando adaptações, ações e reações de todos e para todos.

No presente texto pretendemos tratar destes temas, a partir da interlocução de vários autores que tem pensado principalmente a Sociedade de Riscos em que vivemos e como ela impacta a Democracia, em especial o fenômeno da corrupção enquanto resultado tópico destes cenários.

\section{DESAFIOS À DEMOCRACIA NA SOCIEDADE DE RISCOS}

Podemos concordar com a assertiva de que os tempos de crises econômicas, políticas e institucionais que temos vivido nos últimos anos têm posto ao nosso cotidiano sérios perigos e riscos os mais diversos, inclusive ameaçadores de liberdades e garantias constitucionais. Nestes tempos, a tentação em desconsiderar tais liberdades e garantias está num dos seus pontos mais altos, enquanto a efetividade dos tradicionais checks and balances dos Poderes do Estado e o controle do Mercado e das relações de poder engendradas está num dos seus níveis mais baixos.

Em tempos de crises frequentemente também se argui que determinadas conquistas normativas civilizatórias, eventualmente, podem ser repensadas ou flexibilizadas enquanto prerrogativas que são usufruídas somente em tempos de paz e tranquilidade. Assim, é precisamente nestes tempos que as garantias constitucionais à proteção de direitos e liberdades são postas a prova. Isto nos autoriza a sustentar que os compromissos políticos normatizados internacional e nacionalmente de preservar e manter tais prerrogativas da cidadania devem ser conformados com a cautela sob pena de se transformar os pactos civilizatórios constitucionalizados em suicídio coletivo.'

\footnotetext{
${ }^{1}$ Uma crítica à flexibilização de direitos e garantias fundamentais é feita por GABARDO, Emerson. Os perigos do moralismo político e a necessidade de defesa do direito posto na Constituição da República de 1988. A\&C - Revista de Direito Administrativo \& Constitucional, Belo Horizonte, ano 17, n. 70, p. 65-91, out./dez. 2017.
} 
Por certo que há tensões múltiplas entre valores democráticos e respostas para emergências sociais, institucionais, políticas, econômicas, notadamente quando envolvem riscos e perigos coletivos substanciais, não só quando estamos diante de ameaças terroristas decorrentes dos mais diversos fundamentalismos, mas também quando lidamos com o crime organizado, a lavagem de dinheiro, o tráfico de drogas, de pessoas, de armas, etc., que configuram hoje nichos de Mercado em crescente desenvolvimento descontrolado. ${ }^{2}$ Por tais razões, Philip Heymann sustenta que países democráticos, diante de sérias ameaças ao seu cotidiano, devem manter e proteger a vida e as liberdades necessárias que sustentam esta Democracia, sob pena da perda destes elementos transformar uma saudável e diversificada nação em território dividido e violento.

Ao mesmo tempo, exigências e crises agudas têm desafiado igualmente boa parte dos conceitos da Democracia Constitucional Liberal e Social, muitos deles ampliados no constitucionalismo do século XX, por conta das demandas sociais crescentes e complexas, o que faz surgir, progressivamente, questionamentos sobre qual a extensão, se necessário, da periclitação de valores democráticos fundamentais que pode ser justificada em nome da sobrevivência da própria ordem democrática constitucional? E se elas podem ser justificadas por argumentos públicos razoáveis sob o ponto de vista da legitimidade democrática, em que medida o governo democrático constitucional pode defender ações de Estado sem transformá-lo em regime autoritário?

Tomemos o exemplo dos limites de poder do governo em situações de extrema instabilidade ou demandas sociais urgentes que levam ao fortalecimento conjuntural de um Poder em relação a outro, como é o caso do Executivo em face do Legislativo. Outra forma destas migrações de hegemonia de Poderes é aquela que diz com tradições republicanas e presidencialistas distorcidas - também no Brasil -, nas quais histórica e culturalmente o Poder Executivo tem exercido protagonismo quase que totalitário.

Nesta história de tradição de concentração de poderes nas mãos do Executivo, a habilidade do governo em agir rapidamente, de forma por vezes pouco transparente, mas decisiva contra as ameaças detectadas (algumas reais, outras muito dimensionadas simbolicamente, outras ainda inexistentes), tem feito com que se justifiquem - não raro de forma equivocada - estes comportamentos como processos quase naturais da Política.

De qualquer sorte, crises tendem a expandir poderes governamentais nas mãos daqueles que tem as competências de responder por elas de forma mais direta e ágil, assim como, por vezes, contrair liberdades individuais. Poderes recentemente criados e aprimorados nestas circunstâncias são afirmados pelos governos como necessários para responder aos desafios da comunidade. O problema é que não podemos trata-los

\footnotetext{
${ }^{2}$ SANTANO, Ana Claudia. Uma introdução ao estudo da corrupção política nas sociedades democráticas dentro do paradigma do estado de direito. Paraná Eleitoral, v. 4, p. 123-138, 2015.
} 
como respostas ou ações/reações diretas e definitivas do Executivo em ambientes de crise (modelo permanente de Estado de Emergência), mas como procedimentos de crise a serem avaliados em prestações de contas precisas e amplas a posteriori, passiveis de controles públicos a qualquer tempo. ${ }^{3}$

Determinadas condições de extrema instabilidade política e social criadas por ações violentas, e não precisamos falar de macro problemas internacionais, como o terrorismo, pois, no Brasil, podemos ficar com a recente experiência da intervenção federal civil no Rio de Janeiro, com as forças armadas ${ }^{4}$, tem gerado percepções e conclusões distorcidas sobre adequadas e permanentes políticas públicas preventivas e curativas de Estado a serem tomadas, marcadas, não raro, por radicalismos disjuntivos associados a discriminações étnicas e ideológicas de minorias ${ }^{5}$ Alguns autores chegam a defender que: "as almost always happens, the individuals whose rights are sacrificed are not those who make the laws, but minorities, dissidents, and noncitizens. In those circumstances, 'we' are making a decision to sacrifice 'their' rights-not a very prudent way to balance the competing interests."

Esta forma de compreensão destes temas, como quer Stone, se afigura hoje como politicamente incorreta, razão pela qual poucos a sustentam, mas muitos acreditam em suas premissas, basta atentarmos para a forma cotidiana como alguns governos tratam problemas sociais graves com regras e procedimentos de exceção. Mas quanto disto pode suportar a ordem constitucional contemporânea?

Um grupo de argumentos tem focado estas discussões sobre a ideia dos riscos de ações irracionais que os governos poderiam provocar se assim agissem, devido ao sentimento de pânico generalizado causado por patologias que afligem o cotidiano de instituições e pessoas. ${ }^{6}$ Outra classe de argumentos sugere que o governo deveria agir sempre racionalmente, mas não para maximizar o bem-estar de toda a política; ao invés disto, ele deveria externalizar parcial ou totalmente os custos de segurança para todos os grupos sociais - e não somente para as maiorias, definindo então quais as que iria atender.

Ambas as perspectivas operam a partir do que podemos chamar de Teoria das Falhas Democráticas, a uma, pelo fato de que geralmente não é claro o que é levado

\footnotetext{
${ }^{3}$ Ver o interessante texto de LEIGHNINGER, Matt. The Next Form of Democracy. Nashville: Vanderbilt University Press, 2012. Ver também o documento The administration of justice during states of emergency, do Alto Comissariado das Nações Unidas sobre Direitos Humanos, conforme o acesso no site <http://www.ohchr.org/ Documents/Publications/training9chapter16en.pdf>.

${ }^{4} \mathrm{~A}$ intervenção federal no Rio de Janeiro é a primeira na vigência da Constituição de 1988, na qual as polícias civil e militar, mais o corpo de bombeiros, junto com o sistema prisional do Estado ficam sob a responsabilidade de um general do Exército.

${ }^{5}$ Ver o texto de COLE, David. Their Liberties, Our Security: Democracy and Double Standards. In $<$ http://scholarship.law.georgetown.edu/cgi/viewcontent.cgi?article=1928\&context=facpub>. Acesso em: 22 jan. 2018.

${ }^{6}$ Ver o texto de APPADURAI, Arjun. La nueva lógica de la violencia. Revista de Occidente, Madrid: Fundación Ortega y Gasset, número 266-267, julio 2003. p. 67-82.
} 
em conta para detalhar a relação entre situação de emergência e medidas para efetivamente enfrenta-las; a duas, porque não se afere com profundidade, anterioridade e permanência, como devem ser enfrentadas estas emergências, com que procedimentos mais adequados para os fins de cumprimento com as obrigações constitucionais e infraconstitucionais vigentes.

De qualquer sorte, podemos concluir que dentre as falhas democráticas mais catastróficas para a sustentabilidade legitima das relações de poder hodiernas - institucionais e sociais - encontra-se o fenômeno da corrupção generalizada e tópica, pois aflige países desenvolvidos e em fase de desenvolvimento, criando situações de fragilização imensa das relações sociais.

\section{A CORRUPÇÃO COMO FENÔMENO MUNDIAL}

Os esforços anticorrupção deveriam não apenas detectar, desencorajar e punir formas particulares de corrupção - a despeito de representarem valores indiscutíveis -, mas deveriam também e fundamentalmente abordar problemas mais profundos que se encontram nas suas causas altamente complexas e dispersas no âmbito das relações institucionais e sociais (globais e locais). ${ }^{7}$

O fenômeno da corrupção sempre esteve muito presente em rotas de conflito de poder entre instituições públicas, privadas, interesses pessoais e corporativos, e tais espaços, com seus acordos de convivência e sobrevivência conjunturais, por mais paradoxal que seja, tem auxiliado na melhor configuração de estruturas (também públicas e privadas) de contenção e prevenção à corrupção. ${ }^{8}$

Frequentemente os processos e procedimentos anticorruptivos, para além de ampliar nossos horizontes sobre as perspectivas positivas de ação e reação à corrupção, também tem gerado mudanças de posturas institucionais e sociais no sentido de sermos menos tolerante em face destes problemas todos. ${ }^{9}$

Veja-se que debates sobre política, em termos históricos e ao menos no Ocidente, como lembra Carl Friedrich ${ }^{10}$ operavam já com a antiga premissa de que o Rei não pode fazer nada de errado. Ocorre que hoje o Estado/Governo contemporâneo não

\footnotetext{
${ }^{7}$ BUTELER, Alfonso. Los sistemas para el control de la corrupción pública en el orden global. Revista de Direito Econômico e Socioambiental, Curitiba, v. 8, n. 3, p. 239-261, set./dez. 2017.

${ }^{8}$ FORTINI, Cristiana; SHERMAM, Ariane. Corrupção: causas, perspectivas e a discussão sobre o princípio do bis in idem. Revista de Investigações Constitucionais, Curitiba, vol. 5, n. 2, p. 91-112, mai./ago. 2018.

${ }^{9}$ BITENCOURT, Caroline Müller; RECK, Janriê Rodrigues. Construção pragmático-sistêmica dos conceitos básicos do Direito Corruptivo: observações sobre a possibilidade do tratamento da corrupção como um ramo autônomo do Direito. A\&C - Revista de Direito Administrativo \& Constitucional, Belo Horizonte, ano 15, n. 62, p. 123-140, out./dez. 2015.

${ }^{10}$ FRIEDRICH, Carl J. Limited Government: A Comparison. Englewood Cliffs: Gallie, 1974. p. 27. Lembra o autor que na própria Idade Média, "Legislation played only a secondary role in the medieval governmental process. Laws were few and legislation rare, and medieval constitutionalism could thus concentrate its attention on the problem of the regulation of the abuse of the monarchic executive's power".
} 
é considerado entidade legal totalmente impessoal, mas encarnação viva de heranças comportamentais as quais alcançam distantes e sombrios tempos passados, que o constituem no presente, direta ou indiretamente.

Nem todo o Estado pré-moderno, moderno e contemporâneo se constituiu desta forma, por óbvio, mas a noção da corrupção quando cotejada em seus contextos demandam limites que são colocados sobre, fundamentalmente, os agentes públicos, os quais, por sua vez, são mantidos - em tempos de câmbios políticos profundos e redesenhos na formatação e no exercício do Poder - através de contenções efetivadas por centros de controles deste Poder (controles internos e externos). ${ }^{11}$

Se o soberano pode ter outros interesses e poderes para se preocupar (que não os públicos exclusivamente), ele também pode ser responsável por isto, eis que a história da política tem demonstrado que desde sempre grupos intermediários da soberania popular no exercício da gestão de interesses comunitários - partidos políticos, grupos de pressão, segmentos do Mercado -, foram mais diligentes no atendimento de demandas próprias do que comunitárias. Inclusive quando o pluralismo político teve lugar mais expressivo na arena pública os controles por abusos cometidos eram deficitários, justamente em face dos níveis de comprometimento no enfrentamento da corrupção.

Daí porque podemos falar da emergência do papel moderno da política.

É certo a urgente necessidade de impormos limites à corrupção, mas isto requer explícitas e eficientes ferramentas adequadas, desde normas jurídicas voltadas para isto, passando por políticas públicas e privadas preventivas, $^{12}$ e controle jurisdicional e social incisivo. Claro que na base de tais elementos temos a premissa de que o conceito de limitação do poder que estamos utilizando não se refere fundamentalmente à diminuição da presença do Estado nas relações sociais e institucionais - inclusive do Mercado - (própria de modelos extremamente liberais), mas o que se pretende é evitar o abuso de autoridade e o desvio de poder. ${ }^{13}$

Não há como conter a política enquanto fenômeno plural intersubjetivo e interinstitucional, ela sempre estará exposta a riscos e perigos de cooptação por forças ilícitas as mais variadas, inclusive aquelas vinculadas à corrupção.

Sob outro ponto de vista, também é preciso termos presente que a arte da Política sempre esteve muito associada com o exercício e a defesa do poder instituído, e isto, ao fim e ao cabo, representava (e ainda representa) em muito autoenriquecimento de alguns protagonistas envolvidos.

\footnotetext{
${ }^{11}$ GESTA LEAL, Rogério. Corrupção, democracia e mercado: horizontes turvos. Revista de Direito Econômico e Socioambiental, Curitiba, v. 8, n. 2, p. 303-329, maio/ago. 2017.

${ }^{12}$ BLANCHET, Luiz Alberto; HACHEM, Daniel Wunder; SANTANO, Ana Claudia (Coord.). Estado, direito e políticas públicas: homenagem ao professor Romeu Felipe Bacellar Filho. Curitiba: Íthala, 2014.

${ }^{13}$ LEAL, Mônia Clarissa Hennig; MORAES, Maria Valentina de. Relações entre Estado, Administração Pública e sociedade: a corrupção como fenômeno multicultural e a afetação dos direitos fundamentais. A\&C - Revista de Direito Administrativo \& Constitucional, Belo Horizonte, ano 18, n. 74, p. 175-192, out./dez. 2018.
} 
Muitos sistemas de governos de certo modo têm operado com a lógica do que podemos chamar de reciprocidade, e com a noção de soberano enquanto corporificação pessoal da virtude. O problema é que pautas de reciprocidade não poderiam significar liberdade para tudo, desconsiderando limites significativos que o Estado de Direito e a Democracia Modernos constituíram para o exercício de qualquer forma de poder (pública ou privada) ${ }_{1}^{14}$ envolvendo concepções vinculadas constitucional e infraconstitucionalmente de deveres éticos e morais para o Administrador Público e Mercado.

É igualmente incontestável que o crescimento das demandas sociais de forma desordenada e massivamente consumista vai gerando situações de instabilidades comportamentais com consequências nefastas em termos de violações de direitos fundamentais individuais e sociais, ${ }^{15}$ ao mesmo tempo em que forma novas tipologias de grupos intermediários de poder - como lobistas de segmentos do Mercado que operam sob a base de tráfico ilícito de influência e corrupção ${ }^{16} \mathrm{~A}$ análise de Theobald no ponto é acertada: "Wars, the acquisition of territory, and the emergence of extractive functions such as taxation and the courvee meant that sovereigns increasingly needed political support and effective work by minions whom they could not easily oversee or coerce".

Estas mudanças fazem surgir práticas tais como ter governos e mercados negociando com grupos por vezes minoritários para conseguir consensos conjunturais aptos a viabilizar interesses (lícitos e ilícitos) das mais diversas ordens. E nestas negociações - que costumam ocorrer ordinariamente entre os hegemônicos segmentos de poder - a ética e o mérito legítimos e legais têm instáveis presenças, fazendo com que o interesse público seja muito mais espoliado do que servido. ${ }^{17}$

Por tais razões discordamos de Scott, para quem, já no século XIX, quando os privilégios comportamentais da aristocracia e seus aliados começaram a ser limitados pelos governos democráticos modernos, o conceito de interesse público como propriedade privada dos donos do poder desaparece, passando-se a considerar o Estado como entidade moral e o exercício da autoridade pública como dever. ${ }^{18}$ Este conceito não desaparece, mas se transforma, no sentido de que passa a ser cooptado por estratégias de aparente regularidade formal, via processos legislativos corrompidos em suas

\footnotetext{
${ }^{14}$ SALGADO, Eneida Desiree. Essay on the constitutional promises of democracy and republic. Revista de Investigações Constitucionais, Curitiba, vol. 4, n. 3. p. 85-100, set./dez. 2017.

${ }^{15}$ BLANCHET, Luiz Alberto; MARIN, Tâmera Padoin Marques. A corrupção como violação de direitos humanos e a necessária efetividade da Lei n 12.846/13. A\&C - Revista de Direito Administrativo \& Constitucional, Belo Horizonte, ano 18, n. 71, p. 267-294, jan./mar. 2018.

${ }^{16}$ Sob o ponto de vista mais filosófico e sociológico, ver os trabalhos de: (i) CASTEL, Robert. L'insécurité sociale. Qu'est-ce qu'être protégé? Paris: Edition du Seuil, 2003; (ii) AXEL, Honneth. La Sociedad del Deprecio. Madrid: Trotta, 2005.

${ }^{17}$ Ver o texto de FERRY, Luc. Diante da crise: materiais para uma política de civilização. Rio de Janeiro: Editora Difel, 2010.

${ }^{18}$ SCOTT, James C. Comparative Political Corruption. Englewood Cliffs, New Jersey: Prentice-Hall, 1972.
} 
finalidades reais, execuções orçamentárias de órgãos públicos fraudulentas, contratos administrativos viciados, etc. ${ }^{19}$

Estes conflitos persistem hoje.

No cenário internacional, a Tailândia, em sua nova Constituição, incluiu dispositivos específicos sobre políticas extensivas anticorrupção, desenhados a partir de ampla discussão envolvendo movimentos políticos e sociais organizados para resistir aos abusos cometidos por agentes militares, do Mercado e funcionários públicos do Estado. $^{20}$

Demandas para abertura maior no âmbito das relações políticas e institucionais têm sido cada vez mais intensas, e tomadas como essenciais à luta contra a Corrupção, o que tem envolvido esforços imensos para eliminar os chamados fundos secretos presidenciais (recursos públicos cuja disposição é facilitada para os governos), e diminuir o financiamento privado de campanhas eleitorais dos partidos hegemônicos. ${ }^{21}$

Na mesma direção tem caminhado a experiência chinesa nos últimos anos, verificando que amplos desequilíbrios entre a contínua liberalização econômica extensiva e a ausência de reformas do sistema político tem dado causa a vários tipos de comportamentos corruptivos, principalmente no âmbito de serviços e obras públicas. ${ }^{22}$

Na Europa é a realidade e experiência de cada país com o tema que vai gerar diferentes tipos de regulamentações e políticas públicas. Na Suécia e Dinamarca, esta questão não está na agenda política cotidiana, e sequer tem chamado o debate público social, isto porque seus índices de corrupção são ínfimos. ${ }^{23}$ Por outro lado, até em face de circunstâncias similares às da Suécia e Dinamarca, vários Estados da própria União Europeia ainda não adaptaram suas legislações domésticas em face dos tratados e

\footnotetext{
${ }^{19}$ Tratamos disto no livro LEAL, Rogério Gesta. Estado, Administração Pública e Sociedade: novos paradigmas. Porto Alegre: Livraria do Advogado, 2006. Ver também o texto LEAL, Rogério Gesta. Imbricações necessárias entre moralidade administrativa e probidade administrativa. A\&C - Revista de Direito Administrativo \& Constitucional, Belo Horizonte, ano 14, n. 55, p. 87-107, jan./mar. 2014.

${ }^{20}$ Ver o documento Thailand Corruption Report, publicado no sítio <http://www.business-anti-corruption. com/country-profiles/thailand> (acesso em 17 jul. 2017), dizendo que: "All levels of Thai society suffer from endemic corruption. Even though Thailand has the legal framework and a range of institutions to effectively counter corruption, companies may regularly encounter bribery or other corrupt practices. Ousted former Prime Minister Yingluck recently went on trial for negligence and other offences related to the allegedly corrupt implementation of a rice subsidy scheme that reportedly cost the state USD 16 billion. The Organic Law on Counter Corruption criminalises corrupt practices of public officials and corporations. The Thai Penal Code criminalises active and passive bribery of public officials by persons operating in the public or private sector but excludes facilitation payments".

${ }^{21}$ Ver o texto México social: corrupción, el problema en aumento. Excelsior, edição de 17 jul. 2017. Disponível em: <http://www.excelsior.com.mx/nacional/2017/04/25/1159590>. Diz o periódico que: "De acuerdo con el Inegi, el 83\% de la ciudadanía a nivel nacional, considera que la corrupción es frecuente o muy frecuente en sus estados; destaca asimismo que, en 2015, hubo una entidad, Sinaloa, en donde la corrupción fue percibida como el principal problema de la entidad, aun por arriba de la inseguridad".

${ }^{22}$ Ver o texto de JOHNSTON, Michael, and HAO, Yufan. China's Surge of Corruption. Journal of Democracy, vol. 6, n. 4, p. 80-94, 1995.

${ }^{23}$ Ver o excelente trabalho jornalístico de WALLIN, Claudia. Um país sem excelências e mordomias. São Paulo: Geração Editorial, 2014.
} 
convenções internacionais para o combate da corrupção que foram gerados no período, o que causa certo desequilíbrio de forças preventivas e curativas contra o fenômeno da corrupção.

Um dos pontos talvez que tenha oportunizado convergência de política pública anticorruptiva seja o das novas diretrizes da Comunidade Europeia para os Contratos Públicos e as Licitações, ampliando os níveis de transparência destes atos e, consequentemente, os controles consectários, tomando em conta aqui o fato de que desde a Resolução do Parlamento Europeu de 15 de dezembro de 1995 já há claras orientações neste sentido. ${ }^{24}$

Algumas outras convergências podem ser detectadas em termos de legislação que tende a se uniformizar mais entre os países europeus, equilibrando desde multas e penas, leves e pesadas, dependendo o tipo de corrupção levada a cabo; há normas internas que penalizam de igual forma corruptor e corrompido; em certos Estados-membros somente se penaliza por ato corruptivo o agente público, não o privado que se envolveu de alguma maneira (a não ser por eventual enquadramento em crime contra a administração pública). ${ }^{25}$ Mas são poucos os casos de corrupção nos últimos anos que redundaram em processos de apuração e responsabilização, informa Bernardo Mattarella que:

Sono pochi in tutti gli Stati membri i casi di corruzione di fatto sfociati in processi, forse perché di rado ne sono coinvolti dei singoli che abbiano riportato un danno diretto ai loro interessi e che pertanto sporgono denuncia alle autorità pubbliche. Inoltre i sistemi giudiziari sono spesso oberati di lavoro e riluttanti a occuparsi di tali casi. ${ }^{26}$

Jaime Rodriguez-Arana Muñoz indica que há brechas nas legislações dos Estados da Comunidade Europeia em pontos muito similares, dentre os quais: (a) relacionados às condutas de pedidos de suborno que não são aceitas pelo agente público;

\footnotetext{
${ }^{24}$ Diretiva 2014/24/EU, do Parlamento Europeu e do Conselho, de 26 de fevereiro de 2014. Sobre o tema da transparência e da corrupção em licitações e contratos, ver: AYMERICH CANO, Carlos. Un problema pendiente: la ineficacia de los contratos afectados por actos de corrupción. Revista Eurolatinoamericana de Derecho Administrativo, Santa Fe, vol. 2, n. 2, p. 31-41, jul./dic. 2015; FORTINI, Cristiana; MOTTA, Fabrício. Corrupção nas licitações e contratações públicas: sinais de alerta segundo a Transparência Internacional. A\&C - Revista de Direito Administrativo \& Constitucional, Belo Horizonte, v. 16, n. 64, p. 93-113, abr./jun. 2016; JURUENA, Cynthia Gruenling; FRIEDRICH, Denise Bittencourt. O cumprimento das informações acerca das licitações e contratos celebrados nos portais da transparência: uma análise qualitativa de municípios do Rio Grande do Sul. A\&C - Revista de Direito Administrativo \& Constitucional, Belo Horizonte, ano 17, n. 70, p. 281-307, out./dez. 2017.

${ }^{25}$ RODRÍGUEZ-ARANA MUÑOZ, Jaime. Self-cleaning in public procurement: operational potentiality and regulation in the European Union. A\&C - Revista de Direito Administrativo \& Constitucional, Belo Horizonte, ano 17, n. 70, p. 25-44, out./dez. 2017; RODRÍGUEZ-ARANA MUÑOZ, Jaime. The principles of the global law of public procurement. A\&C - Revista de Direito Administrativo \& Constitucional, Belo Horizonte, ano 16, n. 65, p. 13-37, jul./set. 2016.

${ }^{26}$ MATTARELLA, Bernardo Giorgiio. Controllo della corruzione amministrativa e regole di etica pubblica. Rivista Italiana di Diritto Pubblico Comunitario, 2002, p.45.
} 
(b) a falta de inclusão específica como praticantes de corrupção daqueles que ocupam cargos eletivos; (c) a ausência de responsabilização mais incisiva dos agentes privados envolvidos em atos de corrupção; (d) a falta de regulamentação processual de responsabilização de atos corruptivos praticados por funcionários públicos estrangeiros; (e) a ausência de punição mais incisiva do tráfico ilícito de influência; (f) a regulamentação das situações que envolvem a intimidação dos agentes públicos para instiga-los a agirem contrário às suas obrigações. ${ }^{27}$

Por vezes pode-se perceber que as legislações anticorrupção surgem por decorrência de casos específicos de corrupção mais impactantes no âmbito das mídias e mesmo da formatação da opinião pública os envolvendo, quase como reação defensiva dos organismos estatais e governamentais. ${ }^{28}$ Vide, por exemplo, a notícia veiculada no Brasil:

\section{Medidas anticorrupção chegam à Câmara dos Deputados}

Propostas do governo foram entregues na noite dessa quinta (19). Pedidos têm ressalva de tramitação em urgência

Pacote tem pedidos de tramitação em regime de urgência constitucional de projetos que se encontram na Câmara

O pacote anticorrupção do governo chegou à Câmara dos Deputados, por onde começa a tramitar, e foi protocolado no início da noite dessa quinta-feira (19) na Primeira Secretaria da Casa. Lançado pela presidenta Dilma Rousseff, o pacote é composto por três projetos de lei, uma proposta de emenda à Constituição (PEC) e dois pedidos de tramitação em regime de urgência constitucional de projetos que se encontram na Câmara.

A PEC, que começará a tramitar pela Comissão de Constituição e Justiça (CCJ), onde será apreciada a admissibilidade e constitucionalidade da matéria, propõe alterar a Constituição para dispor sobre a ação civil pública de extinção do direito de posse ou de propriedade proveniente de atividade criminosa, improbidade administrativa ou enriquecimento ilícito. Um dos projetos propõe regulamentar as mudanças propostas na PEC enviada pelo Executivo.

O outro projeto visa alterar a legislação vigente estabelecendo sanções a atividades ilícitas relacionadas a prestação de contas de partido político e de campanha eleitoral. "A proposta visa coibir a prática de conduta conhecida como caixa 2 eleitoral. Tal conduta,

\footnotetext{
${ }^{27}$ RODRÍGUEZ-ARANA MUÑOZ, Jaime. La Directiva Europea de Contratación Pública y la lucha contra la corrupción. Revista de Direito Econômico e Socioambiental, Curitiba, v. 8, n. 1, p. 24-56, jan./abr. 2017.

${ }^{28} \mathrm{LEAL}$, Rogério Gesta. Fundamentos filosóficos e políticos da responsabilidade penal das pessoas jurídicas por atos de corrupção. Revista de Direito Econômico e Socioambiental, Curitiba, v. 7, n. 1, p. 179-219, jan./ jun. 2016.
} 
atualmente, não é penalmente reprimida de modo claro, já que não existe uma tipificação especifica para essa conduta", afirma a exposição de motivos do projeto.

No pacote protocolado na Câmara estão também os pedidos para tramitação em regime de urgência constitucional do Projeto de Lei 5586/05, do Executivo, que tipifica crimes de enriquecimento ilícito quando o funcionário público possui bens incompatíveis com sua renda. A outra urgência é para tramitação do Projeto de Lei 2902/11, também do Poder Executivo, que altera o Código de Processo Penal para dispor sobre medida cautelar de indisponibilidade de bens, direitos e valores de procedência ilícita, entre outros. ${ }^{29}$

\section{CONSIDERAÇÕES FINAIS}

O que podemos desde logo afirmar é que qualquer reflexão e ação sobre a corrupção - em especial nas democracias em consolidação - reclama, de um lado, altos níveis de generalidade em termos de compreensão das suas causas e consequências complexas; por outro lado, também exige foco no enfrentamento e soluções que se possam constituir em face dela.

A despeito disto, é importante termos presente que a consolidação de democracias e mercados são interdependentes em certa medida - o que a história já tem demonstrado. É claro que tal interdependência vai se evidenciar de maneiras distintas em cada experiência política, institucional e social, com diferentes problemas, dificuldades e desafios. Por tais razões os êxitos e fracassos de tal empreitada serão variáveis também. ${ }^{30}$

De igual sorte é importante ter presente que a corrupção tem se mostrado mutante em termos de adaptação às formas de sua contenção e persecução, criando inclusive mecanismos de resistência e defesa a elas, como o patrocínio - pela via de propinas, troca de favores, tráfico ilícito de influência, negociações com setores do Mercado - de redes ou grupos de burocratas estatais. Alguns autores, em face disto, registram importante advertência no sentido de que a corrupção auxilia a consolidação de violações importantes à democracia e suas instituições, mas também provoca para alguns setores - com o sacrifício de muitos - impactos negativos na ordem política, econômica e social. ${ }^{31}$

\footnotetext{
29 Disponível em: <http://www.brasil.gov.br/governo/2015/03/medidas-anticorrupcao-chegam-a-camara-dos-deputados>. Acesso em: 15 abr. 2015.

${ }^{30}$ Ver o interessante texto de PRZEWORSKI, Adam. Sustainable Democracy. Cambridge: Cambridge University Press, 1995. Lembra o autor que tratar a corrupção como uma questão simples e universal em todos os países, já que suas causas e consequencias são muito recorrentes, configura verdadeiro ponto cego (blind spot) em algumas políticas e pesquisas contemporâneas. (p. 54).

${ }^{31}$ Ver o texto de DIAMOND, Larryand; PLATTNER, Marc F. (Eds.) The Global Resurgence of Democracy. Baltimore: Johns Hopkins University Press, 2005.
} 
Em verdade, há situações em que tamanhas são as dificuldades de determinados contextos políticos e sociais, envolvendo profundas crises econômicas e ausência de recursos primários e de infraestrutura para o gerenciamento principalmente de demandas sociais básicas, que ações de corrupção visando atender o interesse de pequenos grupos podem gerar benefícios imediatos de algumas pessoas em estado de necessidade. Como lembra Nye: "Most of the time, people in poor and undemocratic countries face a choice, not between bad and good, but between bad and worse."132 Mas ainda assim os custos morais, éticos, institucionais e de confiança são muito altos e por vezes incomensuráveis.

Estamos convencidos de que os altos níveis de corrupção podem ser reduzidos (ao menos), e esta diminuição deve ser sustentada através de mecanismos preventivos e curativos ou, como sugere John Peters, com um mix de ações concomitantes relacionadas com níveis micro (aprimoramento dos controles interno e externo da Administração Pública, principalmente em todas as fases da gestão, instrumentos de controle de Mercado, políticas públicas transparentes e com participação social nestas áreas), e macro (fortalecimento das instituições democráticas). Ou seja, "just as corruption is an embedded problem in the broader developmental situation, anti-corruption reforms must be interlinked with diverse democratization and economic development strategies." ${ }^{\prime 3}$

Alguns destes aspectos da democratização implicam aberturas reais dos processos políticos formais e materiais de constituição das escolhas/ações públicas e privadas das relações sociais e de poder, assim como de suas premissas necessárias: honestidade, competitividade eleitoral transparente e legítima, ${ }^{34}$ ampliação da participação social na tomada de decisões, ${ }^{35}$ e monitoramento de suas concretizações.

É óbvio que estas medidas reclamam tempo de elaboração e efetivação, o que leva em conta inclusive os processos de resistências institucionais, corporativas e pessoais, pois há universo significativo de interesses atingidos nestas matérias - muitos deles ilícitos. Basta vermos algumas reações curiosas de políticas anticorrupção, que ao invés de gerar governos e mercados mais honestos, têm provocado comportamentos de aceleração de atos corruptivos para os fins de extrair ganhos máximos de cenários

\footnotetext{
${ }^{32}$ NYE, Joseph S. Corruption and Political Development: A Cost-Benefit Analysis. American Political Science Review, vol. 61, n. 2, 1967.p. 422.

${ }^{33}$ PETERS, John G.; WELCH, Susan. Political Corruption in America: A Search for Definitions and a Theory. American Political Science Review, vol. 72, n. 3, 1978. p. 981.

${ }^{34}$ Nesse sentido: SANTANO, Ana Claudia. La Financiación de los Partidos Políticos en España. Madrid: Centro de Estudios Políticos y Constitucionales, 2016.

${ }^{35}$ SCHIER, Adriana da Costa Ricardo; MELO, Juliane Andrea de Mendes Hey. O direito à participação popular como expressão do Estado Social e Democrático de Direito. A\&C - Revista de Direito Administrativo \& Constitucional, Belo Horizonte, ano 17, n. 69, p. 127-147, jul./set. 2017; CARMONA GARIAS, Silvia. Nuevas tendencias en la participación ciudadana en España: ¿socializando la gestión pública o socializando la responsabilidad política? A\&C - Revista de Direito Administrativo \& Constitucional, Belo Horizonte, ano 16, n. 66, p. 29-60, out./dez. 2016.
} 
econômicos e jurídicos instáveis, decorrentes dos processos de transformação lenta de que estamos falando. Por isto questões condizentes a esforços para construir políticas efetivas de participação devem ser concomitantes com os esforços de fortificar instituições democráticas.

Por outro lado, já aprendemos com a história que não existem fórmulas mágicas e receitas prontas de medidas e instrumentos anticorruptivos, tampouco percepções definitivas sobre os estágios de combate, contenção e responsabilização da corrupção, razão pela qual devemos sempre estar abertos aos aprendizados que os fenômenos envolvidos em tais questões se nos apresentam.

\section{REFERÊNCIAS}

AMES, Barry. Os entraves da democracia no Brasil. Rio de Janeiro: Editora FGV, 2003.

APPADURAI, Arjun. La nueva lógica de la violencia. Revista de Occidente, Madrid: Fundación Ortega y Gasset, número 266-267, julio 2003.

AXEL, Honneth. La Sociedad del Deprecio. Madrid: Trotta, 2005.

AYMERICH CANO, Carlos. Un problema pendiente: la ineficacia de los contratos afectados por actos de corrupción. Revista Eurolatinoamericana de Derecho Administrativo, Santa Fe, vol. 2, n. 2, p. 31-41, jul./dic. 2015.

BARRETO, Antonio Rozo. Normalidad y excepcionalidad: la indescifrable regularidad contemporánea de la excepción. Universidad de Palermo, 2007. Disponível em: <http://www.palermo. edu/searchresults.html?q=Antonio+Rozo>. Acesso em: 20 nov. 2017.

BAYER, Peter Brandon. Sacrifice and Sacred Honor: Why the Constitution Is a "Suicide Pact". Questia, 2011. Disponível em: <https://www.questia.com/library/journal/1P3-2566159411/sacrifice-and-sacred-honor-why-the-constitution-is>. Acesso em 08 jan. 2018.

BITENCOURT, Caroline Müller; RECK, Janriê Rodrigues. Construção pragmático-sistêmica dos conceitos básicos do Direito Corruptivo: observações sobre a possibilidade do tratamento da corrupção como um ramo autônomo do Direito. A\&C - Revista de Direito Administrativo \& Constitucional, Belo Horizonte, ano 15, n. 62, p. 123-140, out./dez. 2015.

BLANCHET, Luiz Alberto; HACHEM, Daniel Wunder; SANTANO, Ana Claudia (Coord.). Estado, direito e políticas públicas: homenagem ao professor Romeu Felipe Bacellar Filho. Curitiba: Íthala, 2014.

BLANCHET, Luiz Alberto; MARIN, Tâmera Padoin Marques. A corrupção como violação de direitos humanos e a necessária efetividade da Lei no 12.846/13. A\&C - Revista de Direito Administrativo \& Constitucional, Belo Horizonte, ano 18, n. 71, p. 267-294, jan./mar. 2018.

BUTELER, Alfonso. Los sistemas para el control de la corrupción pública en el orden global. Revista de Direito Econômico e Socioambiental, Curitiba, v. 8, n. 3, p. 239-261, set./dez. 2017. 
CARMONA GARIAS, Silvia. Nuevas tendencias en la participación ciudadana en España: ¿socializando la gestión pública o socializando la responsabilidad política? A\&C - Revista de Direito Administrativo \& Constitucional, Belo Horizonte, ano 16, n. 66, p. 29-60, out./dez. 2016.

CASTEL, Robert. L'insécurité sociale. Qu'est-ce qu'être protégé? Paris: Edition du Seuil, 2003.

COLE, David. Their Liberties, Our Security: Democracy and Double Standards. Georgetown University Law Center, 2003. Dispoível em: <http://scholarship.law.georgetown.edu/cgi/viewcontent.cgi?article=1928\&context=facpub>. Acesso em: 22 jan. 2018.

DIAMOND, Larry; PLATTNER, Marc F. (Eds.). The Global Resurgence of Democracy. Baltimore: Johns Hopkins University Press, 2005.

EBENSTEIN, William. Totalitarismo - Novas Perspectivas. Rio de Janeiro: Bloch, 1967.

ESPOSITO, Roberto. Categorías de loimpolítico. Buenos Aires: Katz, 2006.

FERRY, Luc. Diante da crise: materiais para uma política de civilização. Rio de Janeiro: Editora Difel, 2010.

FORTINI, Cristiana; MOTTA, Fabrício. Corrupção nas licitações e contratações públicas: sinais de alerta segundo a Transparência Internacional. A\&C - Revista de Direito Administrativo \& Constitucional, Belo Horizonte, v. 16, n. 64, p. 93-113, abr./jun. 2016.

FORTINI, Cristiana; SHERMAM, Ariane. Corrupção: causas, perspectivas e a discussão sobre o princípio do bis in idem. Revista de Investigações Constitucionais, Curitiba, vol. 5, n. 2, p. 91-112, mai./ago. 2018.

FRIEDRICH, Carl Joachim. Limited Government: A Comparison. Englewood Cliffs: Gallie, 1974.

GABARDO, Emerson. Os perigos do moralismo político e a necessidade de defesa do direito posto na Constituição da República de 1988. A\&C - Revista de Direito Administrativo \& Constitucional, Belo Horizonte, ano 17, n. 70, p. 65-91, out./dez. 2017.

GIDDENS, Anthony. Runaway world: how globalization is reshaping our lives. New York: Routledge, 2000.

HEYMANN, Philip. Terrorism and America: a commonsense strategy for a democratic society. London: MIT Press, 2000.

HOLMES, Stephen \& SUNSTEIN, Cass R. The Cost of Rights. New York: W. W. Norton \& Company, 1999.

HOWELL, William G. Presidential Power in War. Annual Review of Political Science. Disponível em: <https://www.annualreviews.org/doi/abs/10.1146/annurev-polisci-040609-155927>. Acesso em: 21 mar. 2018.

JOHNSTON, Michael, and HAO, Yufan. China's Surge of Corruption. Journal of Democracy, vol. 6, n. 4, p. 80-94, 1995. 
JURUENA, Cynthia Gruenling; FRIEDRICH, Denise Bittencourt. O cumprimento das informações acerca das licitações e contratos celebrados nos portais da transparência: uma análise qualitativa de municípios do Rio Grande do Sul. A\&C - Revista de Direito Administrativo \& Constitucional, Belo Horizonte, ano 17, n. 70, p. 281-307, out./dez. 2017.

LEAL, Mônia Clarissa Hennig; MORAES, Maria Valentina de. Relações entre Estado, Administração Pública e sociedade: a corrupção como fenômeno multicultural e a afetação dos direitos fundamentais. A\&C - Revista de Direito Administrativo \& Constitucional, Belo Horizonte, ano 18, n. 74, p. 175-192, out./dez. 2018.

LEAL, Rogério Gesta. Corrupção, democracia e mercado: horizontes turvos. Revista de Direito Econômico e Socioambiental, Curitiba, v. 8, n. 2, p. 303-329, maio/ago. 2017.

LEAL, Rogério Gesta. Estado, Administração Pública e Sociedade: novos paradigmas. Porto Alegre: Livraria do Advogado, 2006.

LEAL, Rogério Gesta. Fundamentos filosóficos e políticos da responsabilidade penal das pessoas jurídicas por atos de corrupção. Revista de Direito Econômico e Socioambiental, Curitiba, v. 7, n. 1, p. 179-219, jan./jun. 2016.

LEAL, Rogério Gesta. Imbricações necessárias entre moralidade administrativa e probidade administrativa. A\&C - Revista de Direito Administrativo \& Constitucional, Belo Horizonte, ano 14, n. 55, p. 87-107, jan./mar. 2014.

LEAL, Rogério Gesta. Patologias Corruptivas nas relações entre Estado, Administração Pública e Sociedade: causas, consequências e tratamentos. Santa Cruz do Sul: Edunisc, 2013.

LEIGHNINGER, Matt. The Next Form of Democracy. Nashville: Vanderbilt University Press, 2012.

MATTARELLA, Bernardo Giorgiio. Controllo della corruzione amministrativa e regole di ética pubblica. Rivista Italiana di Diritto Pubblico Comunitario, 2002.

NYE, Joseph S. Corruption and Political Development: A Cost-Benefit Analysis. American Political Science Review, vol. 61, n. 2, 1967.

PECK, Linda L. Court Patronage and Corruption in Early Stuart England. Boston: Unwin Hyman, 1990.

PETERS, John G.; WELCH, Susan. Political Corruption in America: A Search for Definitions and a Theory. American Political Science Review, vol. 72, n. 3, 1978.

RODRÍGUEZ-ARANA MUÑOZ, Jaime. La Directiva Europea de Contratación Pública y la lucha contra la corrupción. Revista de Direito Econômico e Socioambiental, Curitiba, v. 8, n. 1, p. 24-56, jan/abr. 2017.

RODRÍGUEZ-ARANA MUÑOZ, Jaime. Self-cleaning in public procurement: operational potentiality and regulation in the European Union. A\&C - Revista de Direito Administrativo \& Constitucional, Belo Horizonte, ano 17, n. 70, p. 25-44, out./dez. 2017. 
RODRÍGUEZ-ARANA MUÑOZ, Jaime. The principles of the global law of public procurement. A\&C - Revista de Direito Administrativo \& Constitucional, Belo Horizonte, ano 16, n. 65, p. 13-37, jul./set. 2016.

SALGADO, Eneida Desiree. Essay on the constitutional promises of democracy and republic. Revista de Investigações Constitucionais, Curitiba, vol. 4, n. 3. p. 85-100, set./dez. 2017.

SANTANO, Ana Claudia. La Financiación de los Partidos Políticos en España. Madrid: Centro de Estudios Políticos y Constitucionales, 2016.

SANTANO, Ana Claudia. Uma introdução ao estudo da corrupção política nas sociedades democráticas dentro do paradigma do estado de direito. Paraná Eleitoral, v. 4, p. 123-138, 2015.

SCHIER, Adriana da Costa Ricardo; MELO, Juliane Andrea de Mendes Hey. O direito à participação popular como expressão do Estado Social e Democrático de Direito. A\&C - Revista de Direito Administrativo \& Constitucional, Belo Horizonte, ano 17, n. 69, p. 127-147, jul./set. 2017. 